ORIGINAL ARTICLE

\title{
Can eight weeks of judo and taekwondo physical education improve the health-related fitness of male university students?
}

\author{
Mohammed H.H. Mohammed ${ }^{\mathrm{ABD}}$, Hong J. Choi ${ }^{\mathrm{ABD}}$ \\ King Fahd University of Petroleum \& Minerals, Dhahran, Saudi Arabia
}

Authors' Contribution: A - Study design; B - Data collection; C - Statistical analysis; D - Manuscript Preparation; E - Funds Collection ${ }^{1}$.

\begin{tabular}{|c|c|}
\hline \multicolumn{2}{|l|}{ Abstract } \\
\hline Purpose: & $\begin{array}{l}\text { This study aimed to determine if Judo and Taekwondo in a physical education (PE) setting could improve the } \\
\text { fitness of university students. }\end{array}$ \\
\hline Material: & $\begin{array}{l}\text { Students who registered voluntarily for the courses were considered for the study ( } n=27,18-22 \text { years for } \\
\text { Judo; } n=39,18-22 \text { years for Taekwondo). The control group ( } n=32,20-24 \text { years) was composed of students } \\
\text { who were not part of a physical education course. None of the participants were college athletes nor PE } \\
\text { students. The duration of the courses was eight weeks, twice a week with } 50 \text { minutes per session. Both } \\
\text { courses included training for muscular fitness, flexibility, explosive strength, and cardiovascular fitness. The } \\
\text { courses also included sparring matches and sport-specific training. The following health-related fitness } \\
\text { parameters were measured before and after eight weeks: cardiovascular fitness using the Cooper Test, } \\
\text { muscular endurance using } 60 \text { seconds curl-up test, trunk flexibility using the sit-and-reach test, and explosive } \\
\text { leg strength using the standing long jump test. Parametric tests were applied to detect any effect of the } \\
\text { courses on the students. Differences with } p \leq 0.05 \text { and Vargha-Delaney Common language effect size (VD) } \leq \\
42 \% \text { or } \geq 58 \% \text { were considered as evidence for any improvements in the fitness parameters. }\end{array}$ \\
\hline Results: & $\begin{array}{l}\text { Most of the tested parameters, apart from body composition, improved in both martial arts groups while } \\
\text { those of the control group dropped. These changes were significantly different ( } p \leq 0.05 \text { and VD } \leq 42 \% \text { or } \geq \\
58 \% \text { ). The regular curl-ups and sitting stretch done during the eight weeks improved the muscular endurance } \\
\text { and trunk flexibility of the Judo group, respectively. Moreover, continuous practice of the rolling/falling } \\
\text { technique may have contributed to the improvement in flexibility of the Judo students. }\end{array}$ \\
\hline Conclusions: & $\begin{array}{l}\text { There is evidence that eight weeks of Judo and Taekwondo in a PE context improves the health-related fitness } \\
\text { of male university students. } \\
\text { taekwondo, judo, health-related fitness, physical education, university. }\end{array}$ \\
\hline
\end{tabular}

\section{Introduction}

Judo and Taekwondo are martial arts included in the Olympic Games and are practiced by a multitude of people. These martial arts can provide several fitness benefits to participants [1-3]. This advantage is worth considering when designing activity programs that aim at fighting the negative effects of rising physical inactivity in populations. People are increasingly at risk of losing health-related fitness as they reduce regular participation in physical activity [4]. Moreover, a reduction in physical activity engagement increases the risk of having noncommunicable diseases such as cardiovascular disease and diabetes [4].

Physical education (PE) courses can be a possible setting that can be used to improve the physical fitness for young people. PE curricula aim at providing skills to maintain lifelong personal fitness and help young people recognize the importance of health-related fitness. This can be done through classroom lectures and sports practices. For sport practices, students may know how much their fitness has improved after being trained in the sport.

Studies have shown that children can improve their health-related fitness through PE courses, and PE courses have contributed to giving the daily activity needed by (c) Mohammed H.H. Mohammed, Hong J. Choi, 2020 doi:10.15561/20755279.2020.0206 children to be healthy $[5,6]$. Martial arts such as Judo and Taekwondo are suggested as a good activity to include in a PE curriculum due to their fitness benefits [7]. However, according to us, one of the most intimidating aspects of pursuing martial arts is learning enough to understand what works best for each individual. The different forms of fighting style have certain things in common, yet each practice has its own unique philosophy as well as a physical and mental approach. Thus, students and prospective students never get to explore first-hand, and benefit from the range of opportunities in the martial arts. Despite these challenges, it will still be important to steer martial arts training that will focus on the improvement of the health-related fitness of participants especially in a PE setting. In this regard, Lakes et al. [8] have shown evdence that Taekwondo in a PE context is beneficial to the physical fitness and cognitive abilities of adolescents. Unfortunately, this is the only study to our knowledge that examines the effect of a martial art on health-related fitness variables of adolescents in a PE setting.

Few studies have conducted on the benefit of PE curricula on university students. On the topic of martial arts, Mohammed and Choi [9] showed evidence for the benefits of Judo practice in a PE curriculum at the university setting on trunk flexibility. However, the study was limited by a lack of a control group. Since PE aims to 
provide fitness to students, and considering the few studies that exist on the effect of martial art in a PE context on health-related fitness, this study aimed to determine if there was any evidence that Judo and Taekwondo can be useful as PE courses for university students. The hypothesis was that there would be evidence that both martial arts in a PE setting will improve the fitness of students. The study will add to the little available studies that determine the fitness benefits of Judo and Taekwondo on non-athletes.

\section{Materials and Methods}

Study Location, Physical Education Context, and Participants

The study was conducted during the first semester of the 2018-2019 academic year at King Fahd University of Petroleum \& Minerals (KFUPM), Dhahran, Eastern Province of Saudi Arabia. Students who registered voluntarily for the courses were considered for the study $(\mathrm{n}=27,18-22$ years for Judo; $n=39,18-22$ years for Taekwondo). The control group ( $\mathrm{n}=32,20-24$ years) was composed of students who were not part of a physical education course. None of the participants were college athletes nor PE students.

Informed Consent for Human Participants

The study was conducted in accordance with The Code of Ethics of the World Medical Association (Declaration of Helsinki) and approved by the Research Scientific Committee at the Physical Education Department of KFUPM. The participants signed consent forms.

\section{Training Protocol}

\section{Judo course}

The Judo course was conducted twice a week for eight weeks with each session lasting 50 minutes. The students were taught routine exercises with different training drills. Fitness training was achieved by 50 push-ups and 100 curl-ups, two sets for each session, at the beginning and end. Stretching exercises, rolling and falling techniques, and ground techniques were trained for flexibility.

Judo's footwork and steps technique were taught to train for agility. For full body strength and endurance, the randori (practice game) was applied for the effect of improving explosive power (at any second for throws for Ippon) and endurance (to be able to last for a four-minute fight using all muscles let alone lungs). The cardiovascular training was executed with five minutes of circuit training (burpee, jump rope, and jumping jack). Mental training and tactics were also taught through training and the randori.

\section{Taekwondo course}

The course was conducted twice a week for eight weeks. Each session was 50 minutes and taught different training drills: punching, kicking, forms, steps/stances, and free sparring, etc. Fitness training was achieved by 50 push-ups and 100 curl-ups, two sets for each session, at the beginning and end. Sitting stretches and various kicking techniques were executed to increase flexibility. Footwork/step for all directions and combinations of kicking techniques were taught for speed, agility and reaction time. There were three minutes of free sparring to train muscular strength and endurance. Cardiovascular training was done with five minutes of circuit training. Mental training and strategies for fighting were also taught through routine training and sparring.

Testing of Selected Health-related Fitness Variables

The following fitness parameters were tested before and after the course: cardiovascular fitness using the Cooper Test, explosive strength using standing long jump, abdominal muscle endurance using 30s curl-up test, trunk flexibility using the sit-and-reach test, and body composition using body mass index (BMI). All parameters except for explosive strength were tested according to the ACSM health-related fitness testing guidelines [10]. Body mass and height were measured with a stadiometer (Seca GmbH \& Co. KG, Hamburg, Germany). For the standing long jump test, the students were asked to jump forward from a marked line and land with their two feet. They were asked to place their toes behind the marked line and to swing their arms and bend their knees before they jumped. The measurement was taken using a straight inelastic measuring tape taped to the floor. The length jumped was measured at the back of their heel.

All the fitness tests were demonstrated to the students before they proceeded. The students were encouraged to give their maximum effort during the pre and post tests. They were reassured that the values of the tests would not affect their final grade.

Statistical Analysis

SPSS 16 and $\mathrm{R}$ were used for data analysis. $\mathrm{R}$ was used whenever some outputs were not available in SPSS. Parametric tests were used to analyze the data. The Welch t-test was used to compare the baseline values between the exercise groups and the control group. The paired t-test was used to detect differences between the pre and post results. The gains analysis was used to determine if the changes during the eight weeks in both exercise groups were significantly different from the changes in the control group during the eight weeks [11]. The Judo and Taekwondo groups were not compared with each other as the aim of the study was only to determine if both courses were useful in a PE setting. The common language effect size improved by Vargha-Delaney (VD) was used to determine the effect size [12]. When comparing within a group, it tells you the probability that a person will experience a change after undergoing an intervention. When comparing between groups, common language effect size determines the probability that a person randomly selected from one group will be different from another person randomly selected from the other group [13]. Differences with $p \leq 0.05$ and VD $\leq 42 \%$ or $\geq 58 \%$ were considered evidence for any improvements. The VD was calculated using the orddom package in $\mathrm{R}$ [14].

\section{Results}

Data from 98 students ( $\mathrm{N}=27$ for Judo, $\mathrm{N}=39$ for Taekwondo, $\mathrm{N}=32$ for the control group) were analyzed. The age range for the Judo, Taekwondo, and control groups were 18-21 years, 18-22 years, and 20-24 years, respectively. Table 1 shows the pre results. The 
students differed in most of the parameters except for cardiorespiratory fitness. Thus, the changes from pre to post were evaluated. Table 2 displays the pre and post results. The students in both courses improved in all parameters except body mass and BMI. Another exception was that students in the Judo group did not have significant improvements in cardiorespiratory fitness while the Taekwondo group did not improve in flexibility. Table 3 illustrates how the net changes of both martial arts groups differ from that of the control group. The net

Table 1. Differences in baseline data of exercise groups to control group

\begin{tabular}{|c|c|c|c|c|c|c|c|}
\hline \multirow[b]{2}{*}{ Variable } & \multicolumn{3}{|l|}{ Mean (SD) } & \multirow{2}{*}{$\begin{array}{l}\text { p-value, } 95 \% \\
\text { Cl (JG vs CG) }\end{array}$} & \multirow{2}{*}{$\begin{array}{l}\text { VD (JG } \\
\text { vs CG) }\end{array}$} & \multirow{2}{*}{$\begin{array}{l}\text { p-value, } 95 \\
\% \mathrm{Cl} \text { (TG vs } \\
\text { CG) }\end{array}$} & \multirow{2}{*}{$\begin{array}{l}\text { VD (TG } \\
\text { vs CG) }\end{array}$} \\
\hline & Judo ( $N=27$ ) & $\begin{array}{l}\text { Taekwondo } \\
(\mathrm{N}=39)\end{array}$ & $\begin{array}{l}\text { Control } \\
(\mathrm{N}=32)\end{array}$ & & & & \\
\hline Body Mass (kg) & $64.8(12.0)$ & 69.7 (14.9) & $76.0(18.6)$ & $\begin{array}{l}0.01 \\
(-19.6,-2.9)\end{array}$ & $39.9 *$ & $\begin{array}{l}0.120 \\
(-14.2,1.7)\end{array}$ & $32.0^{*}$ \\
\hline $\begin{array}{l}\text { Body Mass Index } \\
\left(\mathrm{kg} / \mathrm{m}^{2}\right)\end{array}$ & $22.27(4.21)$ & $22.93(4.22)$ & $25.41(6.05)$ & $\begin{array}{l}0.027 \\
(-5.91,-0.37)\end{array}$ & $37.9 *$ & $\begin{array}{l}5.47 \times 10^{-2} \\
(-5.02,0.05)\end{array}$ & $33.5^{*}$ \\
\hline $\begin{array}{l}\text { Curl Up (number } \\
\text { of repetitions) }\end{array}$ & $41(8)$ & $41(11)$ & $28(6)$ & $\begin{array}{l}4.16 \times 10^{-9} \\
(9,16)\end{array}$ & $87.1^{*}$ & $\begin{array}{l}2.98 \times 10^{-8} \\
(9,17)\end{array}$ & $89.9 *$ \\
\hline $\begin{array}{l}\text { Sit and Reach } \\
(\mathrm{cm})\end{array}$ & $32(7)$ & $33(7)$ & $29(5)$ & $\begin{array}{l}0.098 \\
(-1,6)\end{array}$ & $64.7^{*}$ & $\begin{array}{l}1.61 \times 10^{-2} \\
(1,7)\end{array}$ & $65.3^{*}$ \\
\hline $\begin{array}{l}\text { Standing Long } \\
\text { Jump (cm) }\end{array}$ & $184.0(23.4)$ & $185.7(20.7)$ & $172.2(24.8)$ & $\begin{array}{l}0.067 \\
(-0.8,24.5)\end{array}$ & $67.5^{*}$ & $\begin{array}{l}1.50 \times 10^{-2} \\
(2.5,24.5)\end{array}$ & $66.9 *$ \\
\hline Cooper Test (m) & 1856 (339) & 1810 (388) & $1830(338)$ & $\begin{array}{l}0.772 \\
(-151,203)\end{array}$ & 44.8 & $\begin{array}{l}0.823 \\
(-194,155)\end{array}$ & 51.7 \\
\hline
\end{tabular}

Note: $\mathrm{Cl}=$ Confidence Interval, VD = Vargha-Delaney common language effect size, JG = Judo course, TG = Taekwondo course, $C G=$ Control group. ${ }^{*} p \leq 0.05$ and VD $\leq 42 \%$ or $\geq 58 \%$, meaning significant difference.

Table 2. Baseline vs post comparisons

\begin{tabular}{lllllll}
\hline Variable & Group & $\begin{array}{l}\text { Baseline Mean } \\
\text { (SD) }\end{array}$ & $\begin{array}{l}\text { Post Mean } \\
\text { (SD) }\end{array}$ & $\begin{array}{l}\text { Mean } \\
\text { difference }\end{array}$ & p-value, 95 \% Cl & VD \\
\hline \multirow{2}{*}{ Body Mass } & JG & $64.8(12.0)$ & $64.9(12.1)$ & 0.1 & $0.749(-0.6,0.8)$ & 50.7 \\
(kg) & TG & $69.7(14.9)$ & $71.3(16.3)$ & 1.5 & $7.72 \times 10^{-4}(0.7,2.4)$ & 52.9 \\
& CG & $76.0(18.6)$ & $77.6(18.9)$ & 1.6 & $2.99 \times 10^{-6}(1.0,2.1)$ & 53 \\
& JG & $22.27(4.21)$ & $22.30(4.18)$ & 0.03 & $0.804(-0.20,0.26)$ & 50.3 \\
BMI (kg/m ${ }^{2}$ ) & TG & $22.93(4.22)$ & $23.41(4.63)$ & 0.48 & $9.29 \times 10^{-4}(0.21,0.75)$ & 53.3 \\
& CG & $25.41(6.05)$ & $25.93(6.15)$ & 0.52 & $2.73 \times 10^{-6}(0.34,0.71)$ & 53.7 \\
Curl Up & JG* & $41(8)$ & $54(10)$ & 14 & $2.51 \times 10^{-10}(11,17)$ & 85.3 \\
(number of & TG* & $41(11)$ & $54(16)$ & 13 & $8.59 \times 10^{-12}(10,15)$ & 75.8 \\
repetitions) & CG* & $28(6)$ & $26(6)$ & -2 & $1.23 \times 10^{-5}(-3,-2)$ & 38.9 \\
& JG* & $32(7)$ & $35(7)$ & 3 & $1.16 \times 10^{-6}(2,4)$ & 64 \\
Sit and Reach & TG & $33(7)$ & $34(7)$ & 1 & $3.42 \times 10^{-2}(0,2)$ & 54.6 \\
(cm) & CG* & $29(5)$ & $28(6)$ & -2 & $3.09 \times 10^{-4}(-3,-1)$ & 40.2 \\
& JG* & $184.0(23.4)$ & $192.2(21.8)$ & 8.1 & $3.85 \times 10^{-3}(2.9,13.4)$ & 59.7 \\
Standing Long & TG* & $185.7(20.7)$ & $191.7(22.8)$ & 6.0 & $1.26 \times 10^{-2}(1.4,10.7)$ & 59.2 \\
Jump (cm) & CG* & $172.2(24.8)$ & $164.8(22.8)$ & -7.5 & $6.29 \times 10^{-6}(-10.3,-4.7)$ & 40.8 \\
& JG & $1856(339)$ & $1944(304)$ & 88 & $0.102(-19,197)$ & 59.8 \\
Cooper Test & TG* & $1810(388)$ & $1990(422)$ & 180 & $2.02 \times 10^{-4}(91,268)$ & 65.1 \\
(m) & CG* & $1830(338)$ & $1713(300)$ & -117 & $2.10 \times 10^{-5}(-164,-69)$ & 38 \\
\hline
\end{tabular}

Note: $\mathrm{Cl}=$ Confidence Interval, VD = Vargha-Delaney common language effect size, JG = Judo course, TG = Taekwondo course, $C G=$ Control group. ${ }^{*} p \leq 0.05$ and $V D \leq 42 \%$ or $\geq 58 \%$, meaning significant difference. 
Table 3. Differences in the changes from baseline to post

\begin{tabular}{|c|c|c|c|c|c|c|c|}
\hline \multirow[b]{2}{*}{ Variable } & \multicolumn{3}{|l|}{ Mean (SD) } & \multirow[b]{2}{*}{$\begin{array}{l}\text { p-value, } 95 \% \\
\text { Cl (JG vs CG) }\end{array}$} & \multirow[b]{2}{*}{$\begin{array}{l}\text { VD (JG } \\
\text { vs CG) }\end{array}$} & \multirow{2}{*}{$\begin{array}{l}\text { p-value, } 95 \\
\% \mathrm{Cl} \text { (TG vs } \\
\text { CG) }\end{array}$} & \multirow[b]{2}{*}{$\begin{array}{l}\text { VD (TG vs } \\
\text { CG) }\end{array}$} \\
\hline & Judo ( $N=27)$ & $\begin{array}{l}\text { Taekwondo } \\
(\mathrm{N}=39)\end{array}$ & $\begin{array}{l}\text { Control } \\
(\mathrm{N}=32)\end{array}$ & & & & \\
\hline $\begin{array}{l}\text { Body Mass } \\
(\mathrm{kg})\end{array}$ & $0.1(1.8)$ & $1.5(2.6)$ & $1.6(1.6)$ & $\begin{array}{l}1.48 \times 10^{-3} \\
(-2.3,-0.6)\end{array}$ & 46.0 & $\begin{array}{l}0.921 \\
(-1.0,0.9)\end{array}$ & 26.4 \\
\hline $\begin{array}{l}\text { Body Mass } \\
\text { Index }\left(\mathrm{kg} / \mathrm{m}^{2}\right)\end{array}$ & $0.028(0.58)$ & $0.48(0.84)$ & $0.52(0.52)$ & $\begin{array}{l}1.09 \times 10^{-3} \\
(-0.78,-0.21)\end{array}$ & 46.0 & $\begin{array}{l}0.813 \\
(-0.36,0.29)\end{array}$ & 28.0 \\
\hline $\begin{array}{l}\text { Curl Up } \\
\text { (number of } \\
\text { repetitions) }\end{array}$ & $14(7)$ & $13(8)$ & $-2(3)$ & $\begin{array}{l}1.71 \times 10^{-12} \\
(13,19)\end{array}$ & $96.3^{*}$ & $\begin{array}{l}1.85 \times 10^{-14} \\
(12,18)\end{array}$ & $100.0 *$ \\
\hline $\begin{array}{l}\text { Sit and Reach } \\
(\mathrm{cm})\end{array}$ & $3(2)$ & $1(3)$ & $-2(2)$ & $\begin{array}{l}1.11 \times 10^{-9} \\
(3,6)\end{array}$ & $78.8^{*}$ & $\begin{array}{l}9.64 \times 10^{-5} \\
(1,4)\end{array}$ & $91.4^{*}$ \\
\hline $\begin{array}{l}\text { Standing Long } \\
\text { Jump (cm) }\end{array}$ & $8.1(13.3)$ & $6.0(14.4)$ & $-7.5(7.8)$ & $\begin{array}{l}3.56 \times 10^{-6} \\
(9.7,21.4)\end{array}$ & $78.8^{*}$ & $\begin{array}{l}4.58 \times 10^{-6} \\
(8.1,18.9)\end{array}$ & $86.9 *$ \\
\hline $\begin{array}{l}\text { Cooper Test } \\
\text { (m) }\end{array}$ & $88(272)$ & $180(273)$ & $-117(132)$ & $\begin{array}{l}9.87 \times 10^{-4} \\
(89,322)\end{array}$ & $87.5^{*}$ & $\begin{array}{l}1.51 \times 10^{-7} \\
(197,395)\end{array}$ & $79.7^{*}$ \\
\hline
\end{tabular}

Note: $\mathrm{Cl}=$ Confidence Interval, VD = Vargha-Delaney common language effect size, JG = Judo course, TG = Taekwondo course, $C G=$ Control group. ${ }^{*} p \leq 0.05$ and VD $\leq 42 \%$ or $\geq 58 \%$, meaning significant difference.

changes in the parameters among students who registered for the courses were significantly different from that of the control group, apart from the body mass and BMI.

\section{Discussion}

The hypothesis tested was that there would be evidence of improvements in health-related fitness of the students who completed the courses. The results show that there is evidence that the courses improved most of the parameters tested. Moreover, the fitness of the control group reduced after eight weeks. Despite the difference in age between the groups, all the students were 20-29 years; an age range in which their fitness is comparable [10].

The regular curl-ups and sitting stretch done during the eight weeks improved the muscular endurance and trunk flexibility of the Judo group, respectively. Moreover, continuous practice of the rolling/falling technique may have contributed to the improvement in flexibility of the Judo students. These improvements coincide with previous studies that reported improvements of these parameters after at least eight weeks of Judo training in non-athletes $[9,15]$. The lack of improvement in flexibility from baseline in the Taekwondo group differs with a previous study [3]. One reason for the difference is because this study considers both statistical significance and effect size as a determinant for significant improvements, while Kim et al. [3] considered only statistical significance. This study and that of Kim et al. [3] agree that Taekwondo induces differences from pre to post if only statistical significance is considered.

Both Judo and Taekwondo courses improved the explosive leg strength of the students as shown from the standing long jump test. Masleša et al. [15] also reported an improvement in explosive leg strength after eight weeks of Judo training among intellectually disabled people. For Judo students, the randori practice games were most likely the reason for explosive leg strength improvements. Throwing requires not only good upper body strength but also the use of the legs to provide explosive power [16]. As for the Taekwondo course, footwork and kicking drills performed during the course most likely improved the explosive strength of the students. These kicking drills also improved the explosive leg strength of girls who participated in an after-school Taekwondo program [3]. Regular practice of these drills performed during the sparring sessions most likely contributed to improvements in explosive leg strength.

Interestingly, cardiovascular fitness improved among students in the Taekwondo course but not among students in the Judo course. This contrasts with a study from Kim et al. [3] which did not observe changes in cardiovascular fitness after 12 weeks. In terms of the lack of significant improvements in cardiovascular fitness in the Judo students, it may be because the Judo training was highly anaerobic than aerobic. This may have resulted in a limited exercise stimulus for improvement of the high level of $\mathrm{VO}_{2 \max }[17]$. Thus, further studies are necessary to examine the effects of Judo training on $\mathrm{VO}_{2}$ max . Despite the insignificant improvement in cardiovascular fitness of the Judo students, their change in $\mathrm{VO}_{2 \text { max }}$ was still significantly better than that of the control group. This result highlights why a physical activity in a PE curriculum for students may be beneficial.

There was no significant improvement in body composition. The measure used for body composition, which was BMI, cannot accurately detect whether the participants lost fat mass or gained lean mass or both. Moreover, the duration of the study was probably short to 
perceive significant changes in body composition.

\section{Limitations}

This study cannot be generalized because the sample selected for this study were male students. Secondly, the sample size was the minimum. A larger sample size will make this study reliable to detect any significant effects of the courses. Lastly, participants' daily activity was not recorded and compared. The data would have helped to understand if their daily activity played a role in improving the fitness of the students who took the courses.

\section{Perspectives}

Given the limitations of this study, further study is necessary as to whether martial arts in a PE context can improve the fitness of female or both male and female university students. This is important for university students who find it difficult to make time to perform regular physical activity due to their course load [18] and are interested in performing a martial arts.

Despite the limitations, the current study also adds information on the beneficial effects of a physical activity in a PE context for university students. What will be important is to properly design the curriculum in order to achieve such benefits as shown in previous systematic reviews $[5,6]$.

Moreover, the effect of such a curriculum on behavior needs to be considered. It has been shown that behaviors can change when PE courses are implemented at the university level [19-21]. Moreover, physical activities learned at the university may influence the physical activity lifestyles of students after graduation [22, 23]. Thus, the evidence from our study can be used to encourage students to further engage in physical activity outside of class time and after graduation.

\section{Conclusions}

To summarize, this paper determined whether martial arts in a PE context will provide fitness benefits to male university students. The martial arts chosen for the study were Taekwondo and Judo and the study was conducted for eight weeks. The study provides evidence that male university students can benefit from a Taekwondo and Judo program in a PE context if the course is held for at least eight weeks.

\section{Acknowledgments}

The authors thanks King Fahd University of Petroleum $\&$ Minerals ${ }^{1}$ for making this research possible and all the students and personnel who were part of the study.

\section{Financial support statement}

The authors did not receive any financial support.

\section{Declaration of interest}

The authors reports no conflict of interest.

\section{References}

1. $\mathrm{Bu} \mathrm{B}$, Haijun $\mathrm{H}$, Yong $\mathrm{L}$, Chaohui $\mathrm{Z}$, Xiaoyuan $\mathrm{Y}$, Singh MF. Effects of martial arts on health status: A systematic review. J Evid-Based Med. 20101;3(4):205-19. https://doi.org/10.1111/j.1756-5391.2010.01107.x

2. Fong SSM, Ng GYF. Does Taekwondo training improve physical fitness? Phys Ther Sport. 20111;12(2):100-6. https://doi.org/10.1016/j.ptsp.2010.07.001

3. Kim H-B, Stebbins CL, Chai J-H, Song J-K. Taekwondo training and fitness in female adolescents. $J$ Sports Sci. 2011;29(2):133-8. https://doi.org/10.1080/02640414.2010.525519

4. World Health Organization. WHO. Prevalence of insufficient physical activity. World Health Organization. [Internet]. 2018 [cited 2018 Nov 19]. Available from: http://www.who. int/gho/ncd/risk_factors/physical_activity_text/en/

5. Minatto G, Petroski EL, Silva DAS. Health-related physical fitness in Brazilian adolescents from a small town of German colonization. Rev Andal Med Deporte. 2016;9(2):67-74. https://doi.org/10.1016/j.ramd.2014.09.003

6. Sun C, Pezic A, Tikellis G, Ponsonby A-L, Wake M, Carlin $\mathrm{JB}$, et al. Effects of school-based interventions for direct delivery of physical activity on fitness and cardiometabolic markers in children and adolescents: a systematic review of randomized controlled trials. Obes Rev. 2013;14(10):818-38. https://doi.org/10.1111/obr.12047

7. Winkle JM, Ozmun JC. Martial arts: An exciting addition to the physical education curriculum. $J$ Phys Educ Recreat Dance. 2003;74(4):29-35. https://doi.org/10.1080/07303084.2003.10609199

8. Lakes KD, Bryars T, Sirisinahal S, Salim N, Arastoo S, Emmerson N, et al. The Healthy for Life Taekwondo pilot study: A preliminary evaluation of effects on executive function and BMI, feasibility, and acceptability. Ment Health Phys Act. 2013;6(3):181-8. https://doi.org/10.1016/j.mhpa.2013.07.002

9. MohammedMHH,ChoiHJ.Effect of an 8-weekJudoCourseon MuscularEndurance, TrunkFlexibility, andExplosiveStrength of Male University Students. Sport Mont. 2017;15(3):51-3. https://doi.org/10.26773/smj.2017.10.010

10.American College of Sports Medicine. ACSM's HealthRelated Physical Fitness Assessment Manual. Fourth edition. Philadelphia: Lippincott Williams \& Wilkins; 2013.

11. Salkind NJ. Gain Scores, Analysis of. In: Encyclopedia of Research Design [Internet]. 2455 Teller Road, Thousand Oaks California 91320 United States: SAGE Publications, Inc.; 2010. Available from: http://methods.sagepub.com/ reference/encyc-of-research-design/n162.xml

12.Vargha A, Delaney HD. A Critique and Improvement of the CL Common Language Effect Size Statistics of McGraw and Wong. J Educ Behav Stat. 2000;25(2):101-32. https://doi.org/10.3102/10769986025002101

13.Lakens D. Calculating and reporting effect sizes to facilitate cumulative science: a practical primer for t-tests and ANOVAs. Front Psychol, 2013;4. https://doi.org/10.3389/fpsyg.2013.00863

14.Rogmann JJ. Ordinal Dominance Statistics (orddom): An $R$ Project for Statistical Computing package to compute ordinal, nonparametric alternatives to mean comparison (Version 3.1). [Internet]. 2013. Available from: http://cran.rproject.org/

15.Masleša S, Videmšek M, Karpljuk D. Motor abilities, movement skills and their relationship before and after eight weeks of martial arts training in people with intellectual disability. Acta Gymnica. 2012;42(2):15-26. https://doi.org/10.5507/ag.2012.008 
16.Franchini E, Del Vecchio FB, Matsushigue KA, Artioli GG. Physiological Profiles of Elite Judo Athletes. Sports Med Auckl. 2011;41(2):147-66. https://doi.org/10.2165/11538580-000000000-00000

17.Torres-Luque G, Hernández-García R, EscobarMolina R, Garatachea N, Nikolaidis PT. Physical and Physiological Characteristics of Judo Athletes: An Update. Sports. 2016;4(1): 20. https://doi.org/10.3390/sports4010020

18.Arzu D, Tuzun EH, Eker L. Perceived Barriers to Physical Activity in University Students. $J$ Sports Sci Med. 2006;5(4):615-20.

19.Cardinal BJ, Jacques KM, Levy SS. Evaluation of a university course aimed at promoting exercise behavior. $J$ Sports Med Phys Fitness. 2002;42(1):113-9.

20.DeVoe D, Kennedy C, Ransdell L, Pirson B, DeYoung W, Casey K. Impact of Health, Fitness, and Physical Activity
Courses on the Attitudes and Behaviors of College Students. $J$ Gend Cult Health. 1998;3(4):243-55.

21.Sallis JF, Calfas KJ, Nichols JF, Sarkin JA, Johnson MF, Caparosa S, et al. Evaluation of a University Course to Promote Physical Activity: Project GRAD. Res $Q$ Exerc Sport. 1999;70(1):1-10. https://doi.org/10.1080/02701367.1999.10607725

22.Silas N. Pearman III MAD, RobertF. Valois PhD M, PhD RGS, PhD RPS, J. Wanzer Drane PE P, PhD CAM. The Impact of a Required College Health and Physical Education Course on the Health Status of Alumni. JAm Coll Health. 1997;46(2):77-85. https://doi.org/10.1080/07448489709595591

23.Sparling PB. College physical education: an unrecognized agent of change in combating inactivity-related diseases. Perspect Biol Med. 2003;46(4):579-87. https://doi.org/10.1353/pbm.2003.0091

\section{Information about the authors:}

Mohammed H.H. Mohammed; (Corresponding Author); https://orcid.org/0000-0002-7193-2185; hamdan@kfupm.edu.sa; Department of Physical Education, King Fahd University of Petroleum \& Minerals; Dhahran, Saudi Arabia.

Hong J. Choi; https://orcid.org/0000-0001-7544-8510; junchoi@kfupm.edu.sa; Department of Physical Education, King Fahd University of Petroleum \& Minerals; Dhahran, Saudi Arabia.

\section{Cite this article as:}

Mohammed H.H. Mohammed, Hong J. Choi. Can eight weeks of judo and taekwondo physical education improve the healthrelated fitness of male university students? Physical education of students, 2020;24(2):109-114.

https://doi.org/10.15561/20755279.2020.0206

This is an Open Access article distributed under the terms of the Creative Commons Attribution License, which permits unrestricted use, distribution, and reproduction in any medium, provided the original work is properly cited http://creativecommons.org/licenses/by/4.0/deed.en

Received: 18.02 .2020

Accepted: 21.03.2020; Published: 30.06.2020 